\title{
ADAPTATION OF ENGINEERING FEA-BASED ALGORITHMS TO LCF FAILURE AND MATERIAL DATA PREDICTION IN OFFSHORE DESIGN
}

\author{
Marek Augustyniak \\ Gdansk University of Technology, Faculty of Applied Physics and Mathematics, Gdansk, Poland, and \\ DES ART Ltd., Gdynia, Poland; e-mail address: maugustyniak@mif.pg.gda.pl \\ Piotr Gajewski \\ DES ART Ltd., Gdynia, Poland \\ KRZYSZTOF ŚWIĄTEK \\ Naval Academy, Gdynia, Poland
}

\begin{abstract}
There is an ever growing industrial demand for quantitative assessment of fatigue endurance of critical structural details. Although FEA-based calculations have become a standard in engineering design, problems involving the Low-To-Medium cycle range $\left(10^{1}-10^{4}\right)$ remain challenging. This paper presents an attempt to optimally choose material data, meshing density and other algorithm settings in the context of recent design of the large offshore windfarm installation vessel, VIDAR. In this study, an attempt is made to assess default FEA-based procedures in RADIOSS software by comparing an experimental test against numerical analyses. Standard slender cylindrical ("I") samples as well as originally designed "Z"-shaped samples made of A90 (S690)-grade steel have been loaded at various nominal stress ranges with or without local yielding. A good correlation has been found between FEA results and experimental cycles-to-failure in I-shaped samples, provided the software material data generator is avoided and Smith-Watson-Topper mean stress correction is used. In the case of Z-shaped samples, the calculated cycles-to-initiation of macro-crack is significantly lower (factor of 3 ) from the experiment. The observed discrepancy is argued to be due to stress gradient influence.
\end{abstract}

Keywords: low-cycle fatigue, Finite Element Method, high-strength steel, stress gradient influence

\section{Introduction}

Over the last decade, Finite Element analyses with subsequent Fatigue calculation (further referred to as "FATFEA") have become a standard practice, especially in the automotive, railway, and marine/offshore design. However, several non-trivial questions arise, whenever an engineer attempts to perform reliable fatigue life estimation, including the following:

- What are the sources of uncertainty in FATFEA procedures and how to limit them?

- What is the scatter of material data input? What is its best source? Can the axial test data be used in arbitrary 2D/3D structures?

- Can non-trivial structural details loaded in LCF/MCF range be quantitatively assessed without detailed considerations of Shakedown/Ratchetting?

The literature addressing the listed questions can be roughly divided into material-centered and structure-centered studies. In the first group, laboratory experiments on standardised samples produce data which serve to define and enhance constitutive equations for various steel brands (Basan et al., 2011; Papuga et al., 2012; de Jesus et al., 2012). Numerical modelling is 
seldom used except for studies of the notch effect (Fatemi et al., 2004). The second group, i.e. structure-centered studies, range from development of novel sample shapes (as in the presented work) to the fatigue testing and validation of industrial components and assemblies. These studies lead to two types of practical results: design recommendations or development of numerical algorithms (the latter usually involving linear or non-linear Finite Element analysis). For example, Firat (2011) provided a guidance through the numerical analysis of a rear-axle assembly and correlated it with a full-scale fatigue experiment. Koh (2009) employed FEA in the case of an automotive steering link, presenting a comparison of FATFEA with experimental data. The calculated lives were moderately non-conservative by a maximum factor of three, calling for further refinement of the algorithms. The conference paper by Mercer et al. (2003) is one of the best previews in the field, providing evidence-based guidelines on good and best usage of fatigue numerical analysis, depending on the steel grade and loading scenario.

There is yet a group of studies which does not easily fit the proposed classification. These are the works on time-evolving phenomena of crack propagation (Biglari et al., 2006) and yield zone stability (Kang, 2008). Evolution of the crack and plastic zone is a coupled material-structural phenomenon, and often requires extensions of standard FEA, like XFEM (Richardson et al., 2011) or efficient shakedown predicting methods (Spiliopoulos and Panagiotou, 2012).

This paper faces both the material-related and geometrical issues. An original concept of Z-shaped samples is proposed, exhibiting non-uniform and non-uniaxial stress states while loaded with a standard uniaxial tensile testing machine.

The "MCF" regime (Middle-Cycle-Failure, from $10^{3}$ to $10^{4}$ cycles) is dealt with, with local yield possibly occurring at the very first cycles, but majority of the cross section working in the elastic regime. The analytic difficulty consists in insufficiency of the linear HCF approach, because the ratchetting/shakedown scenarios may develop. On the other hand, it is impossible to represent $10^{3}-10^{4}$ cycles of engineering structure behavior in a direct step-by-step FEA analysis, so some empirical strain-life equation has to be adopted.

In this paper, a set of options is looked for, which provides stable, unbiased (or moderately conservative) fatigue life assessments regardless of the structure and loading scenario. The software has been chosen from among several products available on the market, including LIMIT, FEMFAT, FATEVAS, and DESIGNLIFE. An optimum combination of scientific soundness, flexibility, and price is looked after. RADIOSS Fatigue tools have been finally selected for their unique feature of joining underlying stress/strain calculation with subsequent fatigue analysis. The only major drawback known at the beginning of the study is the lack of Critical Plane E.S.A. (Equivalent Stress Algorithm), claimed in literature as particularly stable and unbiased in multi-axial stress states (Słowik and Łagoda, 2011; Gaier and Dannbauer, 2006). The strain-life strategy has been chosen because it covers both HCF and LCF/MCF ranges, being thus the only choice for a component experiencing at least local yield. Table 1 presents the summary of options involved in this study.

\section{Experiment}

\subsection{Static tensile stress-strain experiment on I-shaped samples}

An uniaxial material testing machine MTS of maximum load capacity of $100 \mathrm{kN}$ with standard clamps was used in all the experimental activities. Full history of clamp and extensometer displacements were recorded. All I-shaped samples used in both static and fatigue experiments were dimensioned as in Fig. 1.

Static tensile tests until rupture performed on three I-shaped samples demonstrated the yield limit of $780 \pm 15 \mathrm{MPa}$ (see Fig. 2). This parameter exceeds by $50 \mathrm{MPa}$ the nominal minimum value specified by the supplier. Young's modulus was estimated at $209 \pm 1 \mathrm{GPa}$, and Ultimate 
Table 1. Fatigue analysis work-flow with analysed algorithm options

\begin{tabular}{|l|l|}
\hline FEA software/strategy & HW Radioss Bulk/Linear Statics \\
\hline FAT tool/strategy & HW Radioss Fatigue Manager/Strain-Life (E-N) \\
\hline Loading type/range & $\begin{array}{l}\text { Stress-controlled, pulsating tension tests; 500-800 MPa } \\
\text { nominal average stresses in I-shaped samples; nominal } \\
\text { stresses in Z-shaped samples not estimable }\end{array}$ \\
\hline Material data source & $\begin{array}{l}\text { Radioss Material Generator or Literature (de Jesus } \text { et al., } \\
2012)\end{array}$ \\
\hline Mesh type/Size & $\begin{array}{l}\text { Solid (I-shaped sample), shell (Z-shaped sample), cell size } \\
\text { from 0.5 to 1.5 mm }\end{array}$ \\
\hline Mean stress correction & Smith-Watson-Topper or Morrow \\
\hline Equivalent stress algorithm & Absolute max. Principal, Huber-Mises or Tresca \\
\hline Surface finish & Rough or polished \\
\hline
\end{tabular}

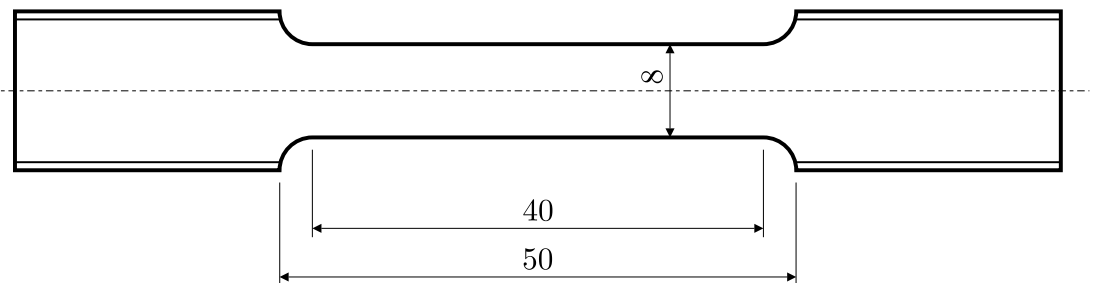

Fig. 1. Dimensioning of I-shaped samples [mm]

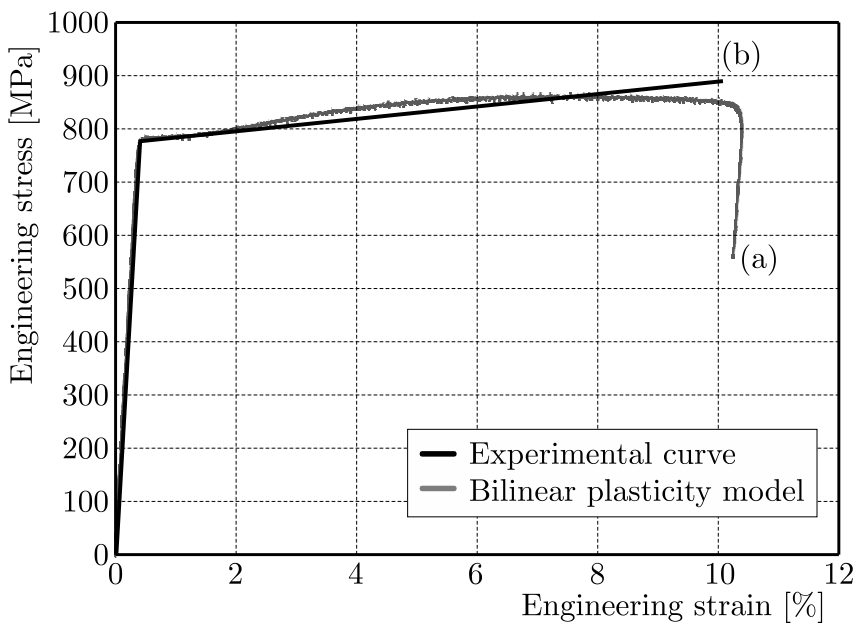

Fig. 2. Engineering stress-strain curve from static monotonic testing until failure; (exp.) - experimental curve, (mod.) - bilinear plasticity model obtained from linear regression of plastic portion of the experimental curve

Tensile Stress (UTS) at $855 \pm 10 \mathrm{MPa}$. Each sample failed statically in the middle of their narrow zone.

\subsection{Fatigue experiments on I-shaped samples}

Stress-controlled fatigue tests were performed on a series of ten I-shaped samples. The cycles had $\sigma_{\min }=0$ and nominal $\sigma_{\max }$ ranging from $500 \mathrm{MPa}$ to $800 \mathrm{MPa}$, producing failure at about 150000 and 7000 cycles, respectively. The pulsating tensile regime was chosen in order to avoid buckling of relatively slender samples. Indeed, I-shaped samples loaded symmetrically at $\pm 740 \mathrm{MPa}$ buckled after 24 and 29 cycles. The measured number of cycles-to-failure for 
10 samples are plotted in Fig. 3. The main frequency of loading was set to $1 \mathrm{~Hz}$, and the maximum frequency used was $3 \mathrm{~Hz}$. Some samples were continuously observed in order to detect the instant of initiation of macrocracks, i.e. the number of Cycles-To-Crack-Initiation (CTCI). A difference between the macrocrack initiation and final failure was not observable. Contrary to the static test, the samples tested in fatigue exhibited a catastrophic crack close to the curved transition zone.

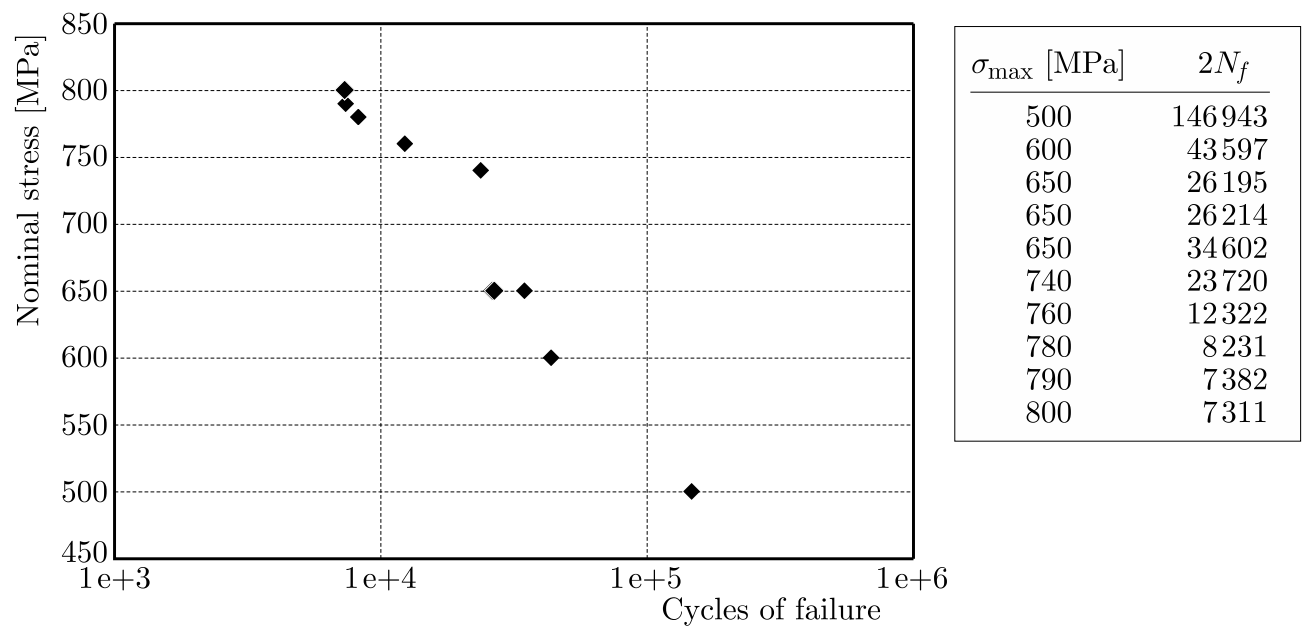

Fig. 3. Semi-log plot of cycles-to-failure obtained from uniaxial stress-controlled loading of I-shaped samples

The data points in Fig. 3 follow a fairly straight line in a log-log scale. The scatter, however, is significant, which made impossible reliable extrapolation of the curve beyond the $10^{3}-10^{4}$ range. Reliable strain-life coefficients had thus to be obtained from other sources, cf. Section 3.2.

\subsection{Fatigue experiments on Z-shaped samples}

Z-shaped samples studied had dimensions as presented in Fig. 4a.
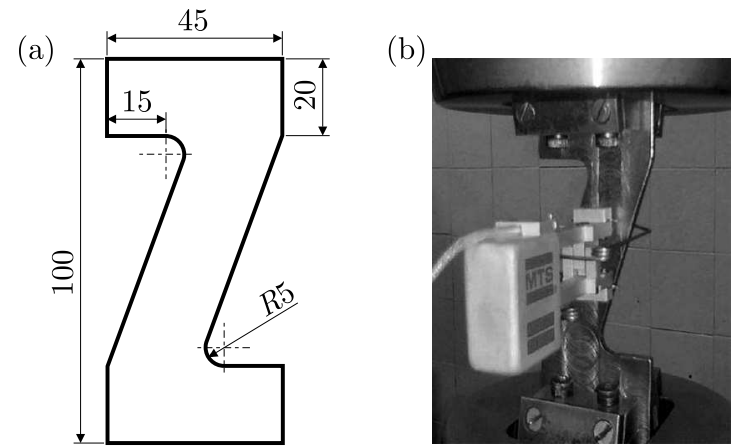

Fig. 4. (a) Dimensioning of Z-shaped samples [mm]. (b) Experimental set-up with an extensometer

Four samples of variable thickness were produced, labeled Z1, Z2, Z3 and Z4. Z4 sample had polished surfaces in order to determine crack initiation time. The samples were placed within the clamps of the tensile test machine (Fig. 4b), and an extensometer with a base set to $20 \mathrm{~mm}$ was installed vertically on the middle section of the sample.

The stress-controlled (constant force amplitude) pulse loading was continued until failure (see Table 2). An approximately linear relationship was found between CTF (Cycles-To-Failure) and sample thickness. During the test of Z4 sample, a movie was recorded with focus on curved regions which were prone to the earliest crack initiation. The movie allowed determination of 
location and time of initiation of a macrocrack observable with a naked eye. This parameter was not determined in the remaining three samples.

Table 2. Number of Cycles-To-Failure and Cycles-To-Initiation of macrocrack in four Z-shaped samples

\begin{tabular}{|c|c|c|c|}
\hline No. & Thickness $[\mathrm{mm}]$ & CTF & CTI \\
\hline \hline Z1 & 4.65 & 4487 & N/A \\
\hline Z2 & 5.35 & 9047 & N/A \\
\hline Z3 & 5.76 & 11183 & N/A \\
\hline Z4 & 6.25 & 14800 & $\sim 9200$ \\
\hline
\end{tabular}

Full clamp and extensometer displacement history was recorded for all the samples. The maximum and minimum clamp displacements in each cycle $\left(d x_{\max }\right.$ and $\left.d x_{\min }\right)$ were extracted from the data, and plotted in Fig. 5.

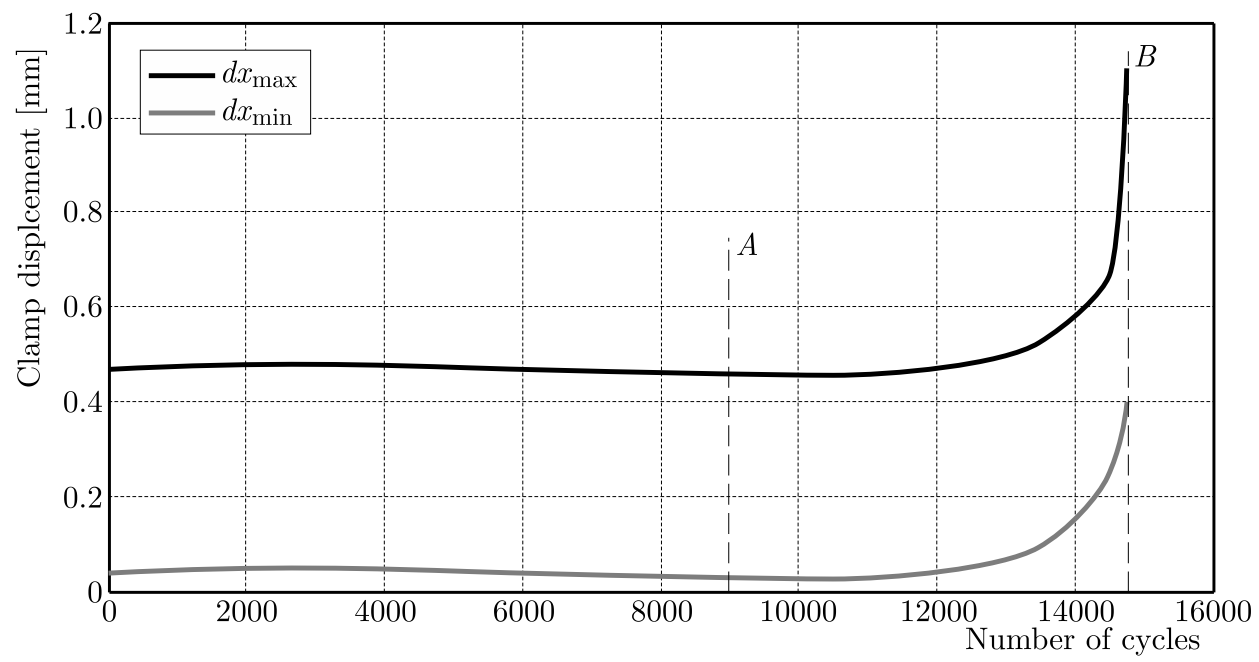

Fig. 5. Clamp displacement envelopes ( $\min / \max )[\mathrm{mm}]$ in $\mathrm{Z} 4$ fatigue test; $A$ - observed macrocrack initiation, $B$ - final failure

The curve recorded for sample Z4 is fairly stable until about $90 \%$ of the total sample life. The observable macrocrack initiated at about 9200 cycles, roughly one half of the entire lifespan of "Z4" Z-shaped sample (14800 cycles). This coincides with the findings of Firat (2011), for a large scale S460 component. Other Z-shaped samples exhibited similar shapes of the displacement $\mathrm{min} / \max$ envelope curves.

\section{Modelling}

\subsection{Discretisation and boundary conditions}

The Finite Element model of I-shaped samples was built in HyperMesh 12.0 pre-processor using hexahedral elements. Each sample was fully constrained at one end and a set of rigid connections was defined at the opposite end to simplify the application of traction force. High-quality elements of edge length of about $1.0 \mathrm{~mm}$ were defined in the curved transition zone. Linear-elastic analyses using a sparse direct solver were performed (Fig. 6).

The Z-shaped samples were modelled with shell elements with $1.0 \mathrm{~mm}$ average edge lengths. The constraints and loading method was similar to that used in the I-shaped samples. Both linear static and elasto-plastic analyses were performed and compared. 


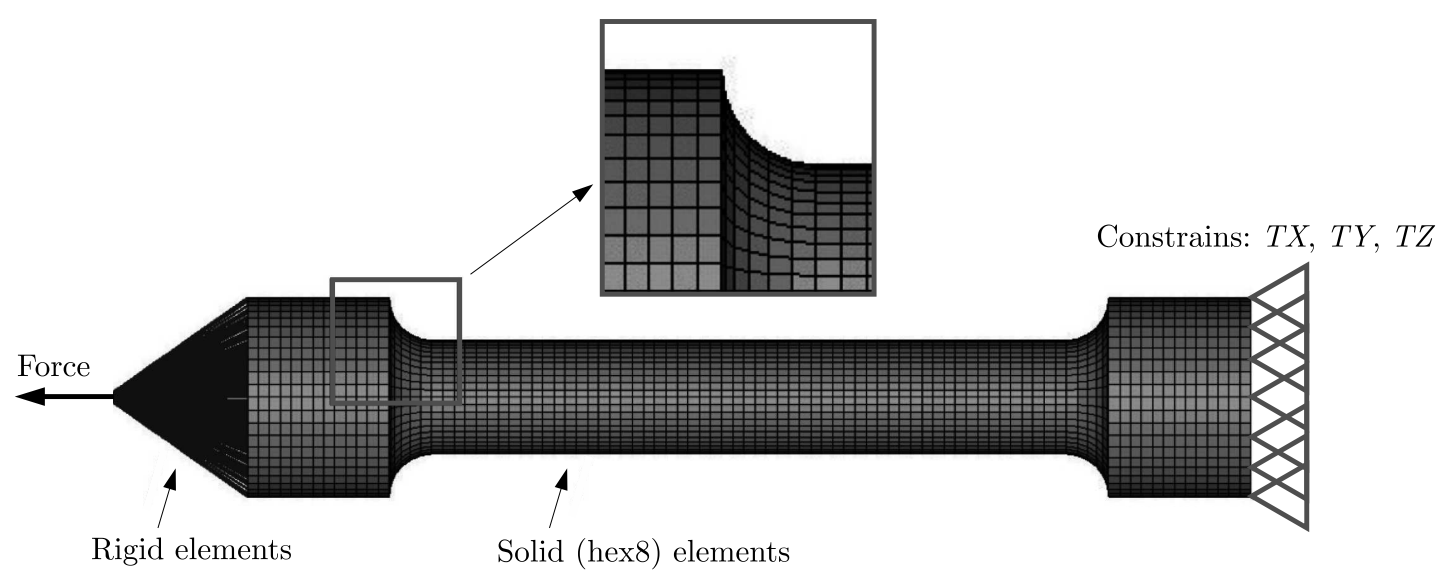

Fig. 6. I-shaped samples: meshing and boundary conditions

\subsection{Material data}

The strain-life fatigue assessment approach was chosen for its versatility and ability to reproduce fatigue characteristics in spots exceeding the yield limit. The required fatigue parameters of the standard Coffin-Manson strain-life equation were either produced in Radioss Material Generator or taken from a detailed study by de Jesus et al. (2012). The Material Generator incorporated in Radioss software required the input of Ultimate Tensile Stress, which was taken from the static tensile experiment with I-shaped samples performed in this study. Table 3 presents a comparison of six coefficients defining the E-N curves in both cases.

Table 3. Coffin-Manson parameters for S690 steel taken from literature (de Jesus et al., 2012) as opposed to those extracted from a numerical Material Data Generator (Radioss software [1])

\begin{tabular}{|c|c|c|c|c|c|c|}
\hline Source & $K^{\prime}[\mathrm{Mpa}]$ & $n^{\prime}[-]$ & $\sigma_{f}^{\prime}[\mathrm{MPa}]$ & $b[-]$ & $\varepsilon_{f}^{\prime}[-]$ & $c[-]$ \\
\hline \hline S690 (de Jesus et al., 2012) & 1283 & 0.09 & 1403 & -0.09 & 0.74 & -0.81 \\
\hline Radioss Material Generator & 1275 & 0.15 & 1403 & -0.09 & 0.51 & -0.58 \\
\hline
\end{tabular}

The plot of both E-N curves (Fig. 7) shows convergence in both very low and very high cycle regions. However, there is a significant discrepancy in the region of interest, namely $10^{2}-10^{5}$ cycles. A given local strain amplitude $\Delta \varepsilon / 2$ may produce CTCI (Cycles-To-Crack-Initiation) estimations from the Material Generator differing by an order of magnitude from those derived from experiment (de Jesus et al., 2012).

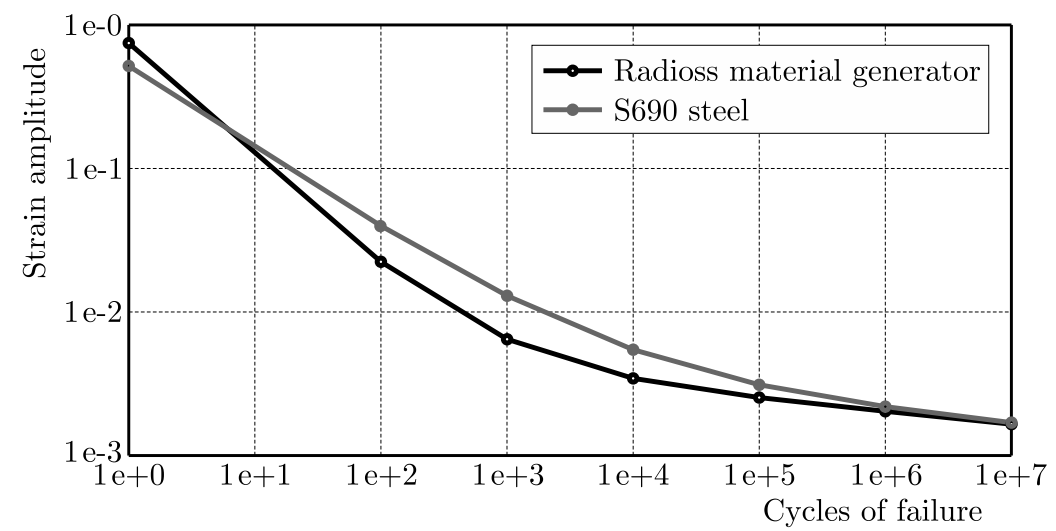

Fig. 7. Comparison of E-N curves (strain amplitude vs. number of cycles) for two sets of constitutive parameters 
The sensitivity of the calculated fatigue life to the choice of E-N curve was studied by comparing FATFEA results against the experimental reference. The details are described in the following Sections.

\section{Results}

\subsection{FEA stresses}

The FATFEA calculation was performed in a standard, two-stage manner. Static stress/strain calculations were followed by application of the fatigue estimation algorithm to each model elements. Figure 8 shows the equivalent von Mises static stress on the surface and across the section cut of a I-shaped sample. The axial tensile force is applied producing the nominal stress of $500 \mathrm{MPa}$. The nominal stress is defined as the ratio of the force to the sample middle cross section area.
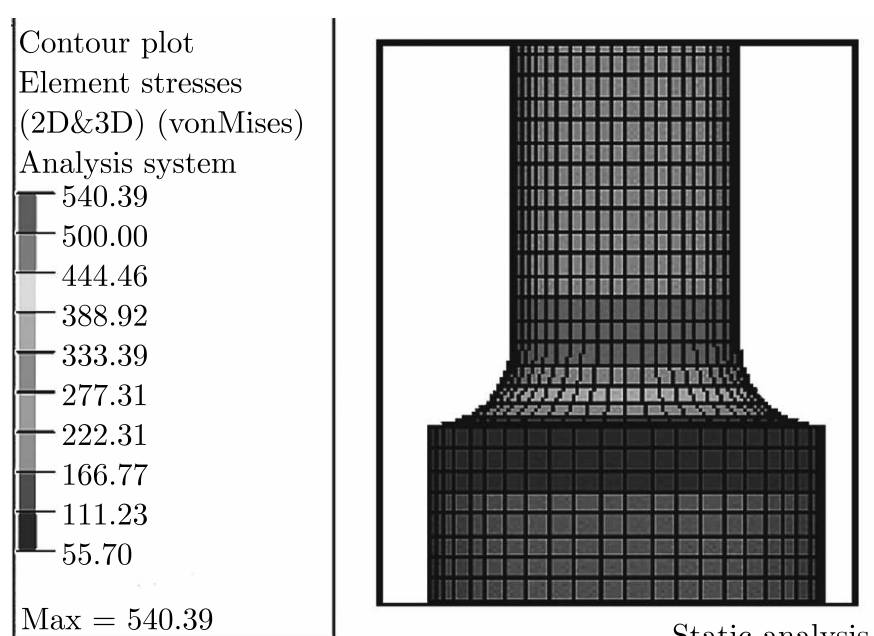

Static analysis $25 \mathrm{kN}$ static force

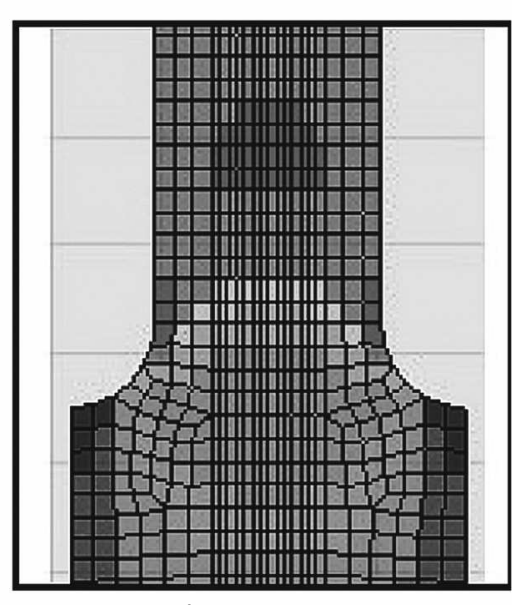

Fig. 8. Equivalent (von Mises) stress distribution on I-shaped sample surface (a) and within its cross-section (b)

As expected, the narrow section far from the transition zone exhibits uniform stresses equal to the nominal ones, as estimated from the ratio of the applied force and the cross-section area. There is a circumferential region of stress amplification at the curved surface. However, the average stress within the transition zone section is inferior to the nominal stress.

A similar static calculation was performed with Z-shaped samples (see Fig. 9a through 9d). Linear-elastic and elasto-plastic approach were compared. The symbol "max" accompanying the result type means that at each shell element its two extreme surfaces were compared and the highest stress value were plotted. For elasto-plastic analysis, a bilinear material model was prepared with the yield limit of $741 \mathrm{MPa}$ and the post-yield tangent modulus of $2 \mathrm{GPa}$. As expected, elasto-plastic analysis (Fig. 9a) produced much lower stress maxima of $749 \mathrm{MPa}$, as compared against $1048 \mathrm{MPa}$ in purely elastic calculation (Fig.9ंb). Consequently, strain values in linear-elastic analysis were much lower compared to elasto-plastic analysis (3.8e-03 vs. 6.3e-03 in Figs. 9c and 9d). The principal stress directions were not disturbed by the introduction of the bilinear elasto-plastic material characteristic.

Although the peak stresses obtained from elastic analysis are unrealistic (significantly above UTS), the area of stresses exceeding yield limit is confined to a single row of elements on the sample edge, so it is allowable to employ the Neuber procedure to deduce the actual strain/stress state in the critical region within fatigue calculation. The results are presented in the following Section. 
(a)

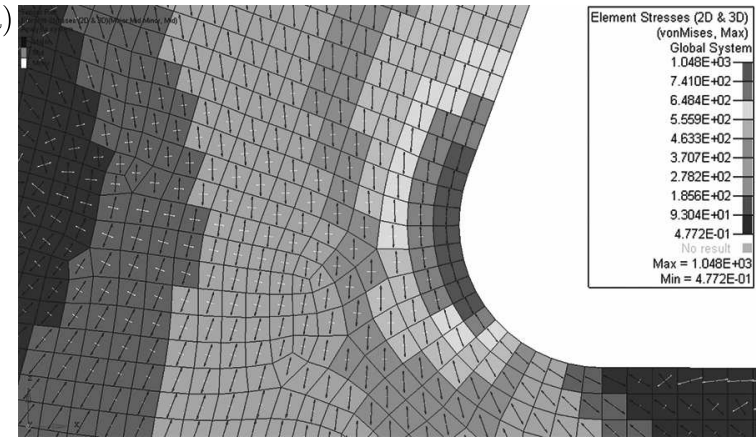

(c)

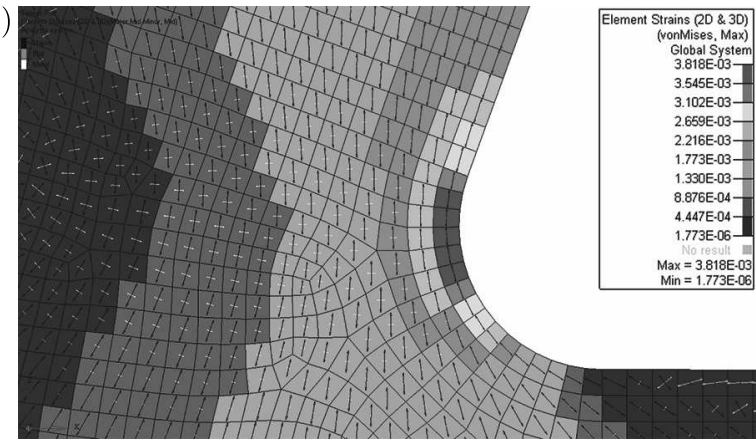

(b)

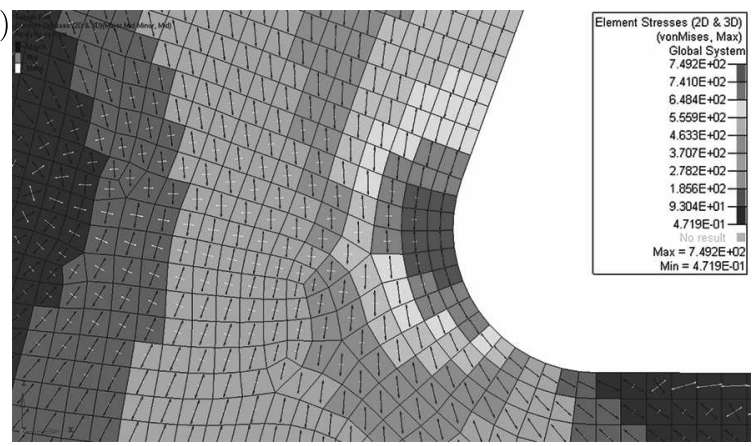

(d)

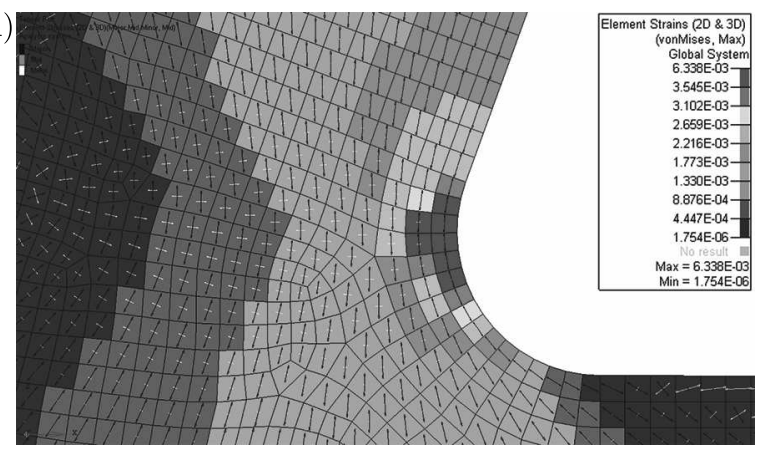

Fig. 9. (a) Linear-elastic calculation and (b) elasto-plastic calculation: contour plot of the equivalent (von Mises) stresses combined with a tensor plot of principal stresses; (c) linear-elastic calculation and (d) elasto-plastic calculation: contour plot of the equivalent (von Mises) strains

It is worth noting that a yet more accurate stress/strain distribution would be obtained if the material cyclic plasticity is modelled, e.g. using Cowper-Symond's model with the mixed isotropic-kinematic hardening. However, such an approach would require additional material parameters, which - unless carefully measured - might introduce an even more significant error. Moreover, step-by-step cyclic plasticity calculation up to hysteresis loop stabilisation is at present impossible in the context of industrial fatigue life assessment of large structures, such as floating vessels.

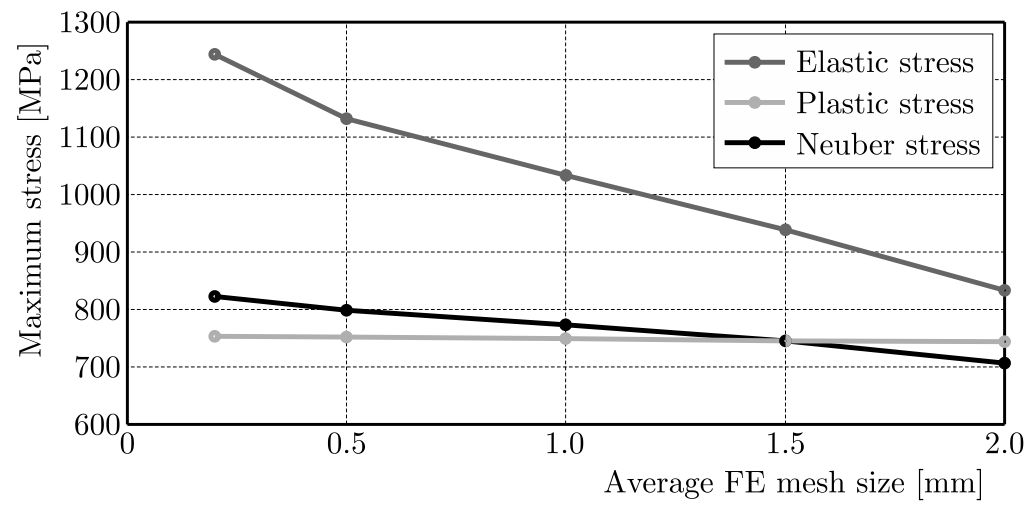

Fig. 10. Comparison of the maximum stresses in Z-shaped samples for different calculation approaches

RADIOSS software did not allow direct fatigue estimation based on elasto-plastic FEA. The widely-known Neuber correction procedure was used instead. The maximum stresses for different mesh sizes were compared (Fig. 10). The purely elastic analysis produces gross overestimation of stress, and this leads to unacceptably conservative fatigue estimates. Involving Neuber's correction leads, however, to peak stress values stably close to those from the elasto-plastic analysis. A particularly good correlation was found for the mesh sizes between 1 and $1.5 \mathrm{~mm}$. 


\subsection{Fatigue life of I-shaped samples}

The fatigue E-N analysis with the Neuber correction and different analysis options was performed referring to the static stress/strain distribution. Different algorithm options were chosen, and the obtained minimum life estimate was compared against experimental CTF (CyclesTo-Failure). The percentage of error was assessed, with positive values corresponding to nonconservative, i.e. highly unfavorable estimation. The selected analysis settings are summarised in Table 4.

Table 4. Scatter of calculated vs experimental fatigue lives in I-shaped samples

\begin{tabular}{|c|c|c|c|c|c|c|c|c|}
\hline $\begin{array}{c}\text { Min/Max } \\
\text { nominal } \\
\text { stress }\end{array}$ & $\begin{array}{c}\text { Material } \\
\text { data } \\
\text { source }\end{array}$ & $\begin{array}{l}\text { Equivalent } \\
\text { stress } \\
\text { algorithm }\end{array}$ & $\begin{array}{l}\text { Mean } \\
\text { stress } \\
\text { corr. }\end{array}$ & $\begin{array}{c}\text { Average } \\
\text { mesh } \\
\text { size }[\mathrm{mm}]\end{array}$ & $\begin{array}{c}\text { Neuber's } \\
\text { correc- } \\
\text { tion } \\
\end{array}$ & $\begin{array}{l}\text { CTCI } \\
(\mathrm{FEA})\end{array}$ & $\begin{array}{l}\text { Experi- } \\
\text { mental } \\
\mathrm{CTF}\end{array}$ & $\begin{array}{c}\text { Relat. } \\
\text { error } \\
{[\%]} \\
\end{array}$ \\
\hline \multirow[t]{8}{*}{$0-500$} & Radioss & Tresca-Guest & SWT & 1.0 & yes & 384350 & 146943 & 162 \\
\hline & S690 & Tresca-Guest & SWT & 1.0 & yes & 146870 & & 0 \\
\hline & S690 & Max. Principal & SWT & 1.0 & yes & 164180 & & 12 \\
\hline & S690 & Huber-Mises & SWT & 1.0 & yes & 227300 & & 55 \\
\hline & S690 & Tresca-Guest & Morrow & 1.0 & yes & 492270 & & 235 \\
\hline & $\mathrm{S} 690$ & Tresca-Guest & SWT & 1.5 & yes & 262580 & & 79 \\
\hline & S690 & Tresca-Guest & SWT & 0.5 & yes & 103100 & & -30 \\
\hline & S690 & Tresca-Guest & SWT & 1.0 & no & 112140 & & -24 \\
\hline \multirow[t]{8}{*}{$0-650$} & Radioss & Tresca-Guest & SWT & 1.0 & yes & 80917 & 26204 & 209 \\
\hline & S690 & Tresca-Guest & $\overline{\mathrm{SWT}}$ & 1.0 & yes & 23157 & & -12 \\
\hline & S690 & Max. Principal & SWT & 1.0 & yes & 25326 & & -3 \\
\hline & S690 & Huber-Mises & SWT & 1.0 & yes & 32944 & & 26 \\
\hline & S690 & Tresca-Guest & Morrow & 1.0 & yes & 48776 & & 86 \\
\hline & S690 & Tresca-Guest & SWT & 1.5 & yes & 37010 & & 41 \\
\hline & S690 & Tresca-Guest & SWT & 0.5 & yes & 17454 & & -33 \\
\hline & S690 & Tresca-Guest & SWT & 1.0 & no & 12580 & & -52 \\
\hline \multirow[t]{8}{*}{$0-800$} & Radioss & Tresca-Guest & SWT & 1.0 & yes & 27253 & 7311 & 273 \\
\hline & S690 & Tresca-Guest & SWT & 1.0 & yes & 7035 & & -4 \\
\hline & S690 & Max. Principal & SWT & 1.0 & yes & 7570 & & 4 \\
\hline & S690 & Huber-Mises & SWT & 1.0 & yes & 9423 & & 29 \\
\hline & S690 & Tresca-Guest & Morrow & 1.0 & yes & 11990 & & 64 \\
\hline & S690 & Tresca-Guest & SWT & 1.5 & yes & 10390 & & 42 \\
\hline & S690 & Tresca-Guest & SWT & 0.5 & yes & 5542 & & -24 \\
\hline & S690 & Tresca-Guest & SWT & 1.0 & no & 3130 & & -57 \\
\hline
\end{tabular}

The 0-500 MPa range was shown to be the most prone to the selection of algorithm options. The bar chart in Fig. 11 shows the relative error committed with wrong modelling assumptions. It is found that the best fit corresponds to the following settings: Smith-Watson-Topper mean stress correction, material data (de Jesus et al., 2012), $1 \mathrm{~mm}$ average mesh size, Tresca Equivalent Stress Algorithm, Neuber correction included.

On the other hand, the worst correlation is associated with the material data taken from default Material Generator, Morrow mean stress correction and with using arbitrary mesh sizing without convergence test. Applying the stress-life algorithm (usually default in FATFEA software) and performing linear static analyses with local plasticity without Neuber's rule are yet more important errors. In the studied case, under most unfavourable conditions, the arithmetic sum of error contributions might reach $+500 \%$, greatly overestimating the structure safe operational life span. 


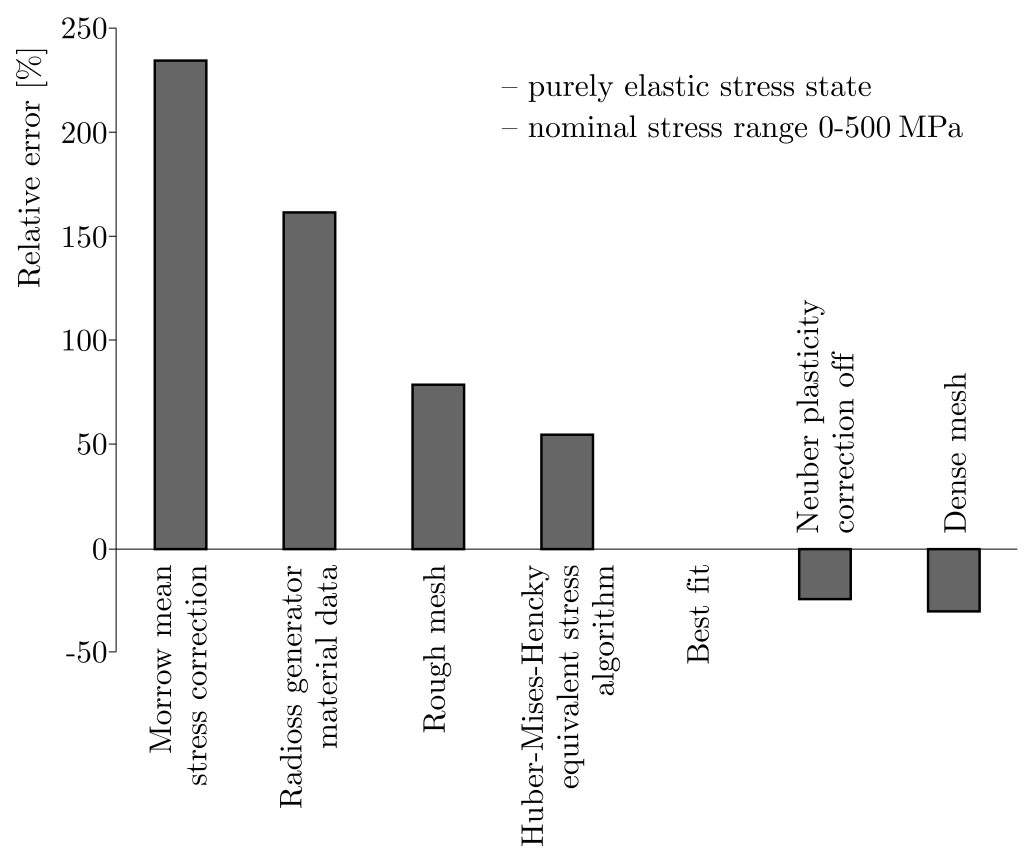

Fig. 11. I-shaped sample, elastic stress range: Discrepancy between the FATFEA result and the experiment for various algorithm settings

\section{3. $\quad$ Fatigue life of $\mathrm{Z}$-shaped samples}

The sensitivity analyses of FATFEA results was subsequently performed in the case of Z-shaped samples. The results of selected computations and the experimental results are presented in Table 5 .

Table 5. Z4-sample: Comparison between the FATFEA result juxtaposed with the experimental observation for various algorithm settings

\begin{tabular}{|l|c|c|c|}
\hline $\begin{array}{c}\text { Equivalent stress } \\
\text { algorithm }\end{array}$ & $\begin{array}{c}\text { Mean stress } \\
\text { correction }\end{array}$ & $\begin{array}{c}\text { Neuber's } \\
\text { correction }\end{array}$ & CTCI \\
\hline \hline Abs. max. principal & SWT & Neuber & 3323 \\
\hline Signed Von Mises & SWT & Neuber & 3541 \\
\hline Signed Tresca & SWT & Neuber & 2983 \\
\hline Signed Tresca & Morrow & Neuber & 4599 \\
\hline Signed Tresca & SWT & none & 1250 \\
\hline Experiment & $\sim 9200$ \\
\hline
\end{tabular}

It is found that the algorithm settings which gave a very good quantitative correlation in the case of I-shaped samples, behave in a significantly conservative way in Z-shaped samples. It is argued that the Neuber correction predicted overly localised concentration of stress/strain. The correlation might be better with FATFEA based on elasto-plastic stress/strain computation. Introducing the correction for the stress gradient would lead to a better agreement, too.

It is argued that in the I-shaped sample, the nearly constant stress over the sample section shortens the lifespan between the crack initiation and the final fracture. The localised nature of peak stress slows down the crack propagation. The Z-shaped sample exhibit thus an optimistic scenario of structural failure. Consequently, FATFEA calibrated on the I-shaped sample leads to conservative, shorter than observed life estimates. Fortunately, the moderate conservatism can be beneficial in the context of engineering design of safety-critical structures. 


\section{Conclusions and perspectives}

The objective of generation of non-1D stress states with a standard 1D tensile test machine has been achieved in this study. The Z-shaped samples produced non-uniform, predominantly biaxial stresses along the crack propagation path.

It is found that the selection of best FATFEA algorithm depends on the level and distribution of the stress/strain maxima. In the case of I-shaped samples loaded below the yield limit, various algorithm settings influence significantly the fatigue estimates. It is possible to select options giving a very good quantitative correlation with the experiment. On the other hand, the scatter of calculated results is much lower in Z-shaped samples, however then the results never approach the experimental data. This observation is primarily accounted for the lack of stress gradient correction and limited applicability of Neuber's algorithm to the yield zones larger than a single row of elements. It is concluded that an analysis based on linear static solution is acceptable as long as mesh convergence tests are performed, and Neuber's algorithm should be applied with caution. It is advisable to compare linear stress/strain results with at least one non-linear, elasto-plastic calculation.

The material data generator based on UTS parameter has proven unreliable in the studied fatigue life range, producing dangerously non-conservative fatigue estimates. An acceptable Material Generator should differentiate between various steel groups (as postulated by Basan et al. (2011)). Unfortunately, no software known to the authors as of the end of 2015 offers such an option.

Morrow's mean stress correction strategy gives as well poor, non-conservative correlations with experiment, in both the I- and Z-shaped samples. Unlike the mean stress correction formula, the equivalent stress/strain algorithm plays a less significant role.

It has been found that the number of Cycles-To-Crack-Initiation (CTCI) and the number of Cycles-To-Failure (CTF) are equal in uniformly stressed samples, but differ in the sample exhibiting stress concentration. In the latter case, CTF could not be reliably predicted with static FEA, and would require detailed cycle-by-cycle study of crack and yield zone evolution, which remains beyond the scope of this article.

\section{References}

1. Altair Ltd: HyperWorks Users' Guide, Radioss Fatigue Manager

2. Basan R., Franulovic M., Prebil I., Crnjaric-Zic N., 2011, Analysis of strain-life fatigue parameters and behaviour of different groups of metallic materials, International Journal of Fatigue, 33, 484-491

3. Biglari F.R., Rezaeinasab A., Nikbin K., Sattarifar I., 2006, Finite Element Simulation of dynamic crack propagation without remeshing, Journal of ASTM International, 3, 7

4. E-Fatigue. Finite Element Model Strain-Life Technical Background, https://www.efatigue.com/fem/background/strainlife.html,

5. Fatemi A., Zeng Z., Plaseied A., 2004, Fatigue behavior and life predictions of notched specimens made of QT and forged microalloyed steels, International Journal of Fatigue, 26, 663-672

6. Firat M., 2011, A computer simulation of four-point bending fatigue of a rear axle assembly, Engineering Failure Analysis, 18, 2137-2148

7. Gaier C., Dannbauer H., 2006, An efficient critical plane method for ductile, semiductile and brittle materials, Conference Proceesings of Fatigue Congress, Atlanta

8. de Jesus A.M.P., Matos R., Fontoura B.F.C., Rebelo C., Da Silva L.S., VelukoviC M., 2012, A comparison of the fatigue behavior between S355 and S690 steel grades, Journal of Constructional Steel Research, 79, 140-150 
9. KANG G., 2008, Ratchetting: recent progresses in phenomenon observation, constitutive modeling and application, International Journal of Fatigue, 30, 1448-1472

10. Кон S.K., 2009, Fatigue analysis of an automotive steering link, Engineering Failure Analysis, 16, 3,914-922

11. Mercer I., Malton G., Draper J., 2003, The effect of user decisions on the accuracy of fatigue analysis from FEA, Conference Proceedings, ABAQUS 2003 Users' Meeting

12. Papuga J., Vargas M., Hronek M., 2012, Evaluation of uniaxial fatigue criteria applied to multiaxially loaded unnotched samples, Engineering Mechanics, 19, 2/3, 99-111

13. Richardson C.L., Hegemann J., Sifakis E., Hellrung J., Teran J.M., 2011, An XFEm method for modelling geometrically elaborate crack propagation in brittle materials, International Journal for Numerical Methods in Engineering, 12, 88(10), 1042-1065

14. SŁowik J., Łagoda T., 2011, The fatigue life estimation of elements with circumferential notch under uniaxial state of loading, International Journal of Fatigue Volume, 33, 9, 1304-1312

15. Spiliopoulos K.V., Panagiotou K.D., 2012, A direct method to predict cyclic steady states of elastoplastic structures, Computer Methods in Applied Mechanics and Engineering, 223/224, $186-198$

Manuscript received January 18, 2016; accepted for print March 10, 2016 